of learning disability services in Sandwell and how they can be accessed.

Geraldine Cassidy, Meera Roy and Thomas MLele, Sandwell Mental Health Service, Newton House Community Unit, 20 Heath Lane, West Bromwich B71 2BD

\section{Publication of MRCPsych examination results}

Sir: I passed the MRCPsych Part I examination held in Autumn 1994 and would like to mention certain doubts which were commonly expressed by the candidates.

First, we are at a loss to understand why it takes the College as long as four weeks to publish the results, particularly since fellow associations like the Royal College of Surgeons, and the Royal College of Physicians are far quicker with their results, with a far larger pool of candidates. The MCQ Paper probably gets corrected by the computer in a matter of days. The clinical part, according to general opinion, gets decided on that day itself, or at the very latest, by the next day. One can understand the delay in publishing the results of the Part II examination, since that involves essay type questions and short answer questions. However, regarding the Part I, one fails to comprehend the reason for the delay. Secondly, I went to a revision course before the examination, where we were told that for the clinical examination, according to College guidelines, separate marks were allotted respectively for history, mental state examination, physical examination, interviewing in front of the examiners, differential diagnosis, aetiology, and investigations. However, in the examination proper, I found that I was not asked a single question about either aetiology or investigations. This obviously led to a lot of soul-searching on my part as to where I had gone wrong. Many candidates had a similar experience and had to wait a month in suspense before their doubts were resolved.

The Membership examination is a stressful experience and the mental state of candidates could be improved, both during and after the examination if the College published the results earlier, and also ensured that its guidelines are enforced more strictly.

Piyal Sen, North West London Mental Health NHS Trust, Central Middlesex Hospital, Acton Lane, London NW10
Working with young offenders: a contribution to forensic training in child peychiatry

Sir: Specialist forensic training posts in child psychiatry are on the increase. However, in a survey of all child and adolescent psychiatry training schemes in the United Kingdom, Reder \& Lucey (1990) found that training with regard to young offenders was virtually absent. The rise in juvenile crime rates together with a contraction in services equipped to deal with antisocial young people, has led to increasing concern among psychiatrists about the health of young offenders: there are particular concerns about suicides among young offenders and about a core group of recidivist offenders.

There is therefore a clear need for specialist training placements which include involvement with young offenders. One such placement exists in North West Thames. The post is equally divided between a children and families department and the regional forensic out-patient department and includes an attachment to Feltham Young Offenders Institution (YOI) for one session of consultation per fortnight.

The placement offers many unique opportunities. First, the modes of presentation of disorders and the difficulties faced in treating them can be seen. Secondly, an insight into the lives of young offenders is gained, which provides a valuable understanding of the routes they have followed into crime and into prison. Finally, the trainee begins to comprehend the influence of a prison environment on prisoners and on therapeutic relationships through the experience of the establishment and through knowledge of a different government department, namely the Home Office.

These experiences are an invaluable assistance in carrying out individual assessments of young offenders for the courts, by helping one think about the impact of prison life on young people. and the level of psychiatric disturbance that can be managed effectively in prison. In addition, the knowledge and skills obtained are particularly relevant when considering consultation work with prison professionals.

In view of the increasing role of child and adolescent psychiatrists in the assessment and management of young people who commit crimes, this area of training can no 